\title{
Propriedades físicoquímicas e avaliação da toxicidade aguda do extrato etanólico padronizado a $70 \%$ das folhas de Mikania glomerata (Asteraceae)
}

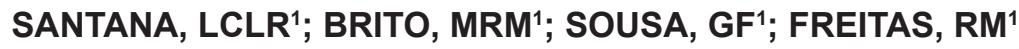 \\ ${ }^{1}$ Laboratório de Pesquisa em Neuroquímica Experimental do Programa de Pós-graduação em Ciências \\ Farmacêuticas, Centro de Ciências da Saúde, Campus Ministro Petrônio Portela, CEP: 64.049-550, Teresina \\ - Brasil. *rivelilson@pq.cnpq.br
}

\begin{abstract}
RESUMO: Mikania glomerata (Asteraceae) é bastante utilizada na medicina popular devido às suas ações broncodilatadora, antiasmática, expectorante e antitussígena. O objetivo do presente estudo foi determinar propriedades físicoquímicas do pó obtido a partir das folhas de M. glomerata, bem como avaliar a toxicidade em camundongos após tratamento agudo com doses repetidas do extrato etanólico padronizado a $70 \%$ preparado durante 30 dias consecutivos. No estudo das propriedades físicoquímicas fez-se a determinação da densidade bruta e de compactação, do teor de cinzas totais, do teor de umidade e da granulometria. De acordo com os resultados obtidos o pó pode ser usado na formulação de uma forma farmacêutica sólida, uma vez que suas propriedades físico-químicas são compatíveis com o desenvolvimento desse tipo de formulação. Na segunda parte do estudo foi determinada a dose letal $50 \%\left(\mathrm{DL}_{50}\right)$ em camundongos, e na análise morfológica macroscópica dos principais órgãos e avaliada a toxicidade aguda com doses repetidas em parâmetros bioquímicos e hematológicos de camundongos. Os resultados sugerem que o extrato etanólico padronizado a $70 \%$ pode ser usado de forma segura, uma vez que apresentou um valor para a $\mathrm{DL}_{50}\left(\sim 3000 \mathrm{mg} \mathrm{kg}^{-1}\right)$ que pode ser classificado na categoria nociva, e não produziu nenhuma alteração morfológica nos principais órgãos e em parâmetros bioquímicos e hematológicos de camundongos.
\end{abstract}

Palavras-chave: Mikania glomerata, Asteraceae, Toxicidade Aguda, Camundongos.

ABSTRACT: Physicochemical properties and acute toxicity evaluation of ethanol extract of the leaves from Mikania glomerata Sprengel. Mikania glomerata Sprengel is a plant from the Asteraceae family and it is widely used in folk medicine because of its bronchodilating, anti-asthmatic, expectorant and antitussive effects. The purpose of this study was to determine the physicochemical properties of the powder obtained from the leaves of M. glomerata, and to evaluate the toxicity in mice after an acute treatment with repeated doses of standardized $70 \%$ ethanol extract prepared from the leaves during 30 consecutive days. To study the physicochemical properties of the powder, we conducted a determination of the bulk density and compaction, the total ash content, the moisture content and particle size. According to the results obtained, we suggest that the powder can be used to formulate a solid dosage form, since its physicochemical properties matches the development of this type of formulation. In the second part of the study, it was determined a lethal dose in the order of 50\% (LD50), along with a gross morphological analysis and the evaluation of the acute toxicity with repeated doses, in the terms of biochemical and hematological parameters of mice. According to the results from the second phase, we suggest that the $70 \%$ ethanol extract can be used safely in humans, since it presented a value for the LD50 $\left(\sim 3000 \mathrm{mg} \mathrm{kg}^{-1}\right)$ that can be classified as 'harmful'. It also did not produce any morphological changes in the major organs and in the biochemical and hematological parameters of mice.

Keywords: Mikania glomerata, Asteraceae, Acute toxicity, Mice.

\section{INTRODUÇÃO}

Mikania glomerata (Asteraceae) possui

folhas opostas, simples, acuminadas e flores brancas (Teske \& Trentini, 1997). Essa espécie é conhecida popularmente por diversos nomes dentre eles guaco, guaco trepador, guaco-de-cheiro, guaco liso, erva de cobra, cipó catinga e coração 
de Jesus (Celeghini et al., 2001). Asteraceae é uma das maiores famílias das Angiospermas, com aproximadamente 1535 gêneros e 23.000 espécies (Bremer, 1994). O gênero Mikania Willd. caracteriza-se por plantas herbáceas, anuais ou perenes, subarbustivas e escandentes (Pio Corrêa 1984; Leite et al.,1993).

A planta em questão é originária da América do Sul, ocorrendo espontaneamente no Brasil e também no Uruguai, na Argentina e no Paraguai (Celeghini et al., 2001). No Brasil, ocorre de norte a sul, tendo sua principal área de dispersão nos estados de Minas Gerais, Rio de Janeiro e São Paulo (Oliveira, 1972; Ritter \& Miotto, 2005). M. glomerata Sprengel é uma planta medicinal bastante empregada na medicina popular devido as suas propriedades broncodilatadora, antiasmática, expectorante e antitussígena (Panizza, 1997).

O estudo fitoquímico dessa espécie demonstrou a presença em sua composição química de cumarina (A), lupeol (B), friedelina (C) Taleb-Contini et al. (2006), ácido caurenóico (D), ácido cinamoilgrandiflórico (E) (Lucas, 1942; Oliveira et al., 1984) estigmast- 22-en-3-ol (F) Oliveira et al. (1984), ácido 15-a-isobutiriloxicaur16-en-19-óico (G) Veneziane (1999), ent-caur16(17)-em-19-óico (H), ent-15- $\beta$-isobutiloxicaur16(17)-em-19-óico (I), ent-15- $\beta$-benzoioxicaur16(17)-en-19-óico (J), ent-15- $\beta$-hidroxicaur16(17)-em-19-óico (K), ent-17-hidroxicaur-15(16)em-19-óico (L), o-hidroxicinâmico (M) (Figura 1)<smiles>O=c1ccc2ccccc2o1</smiles>

(A)

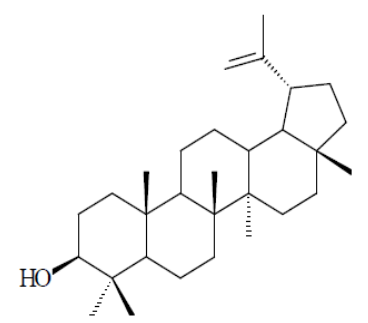

(B)

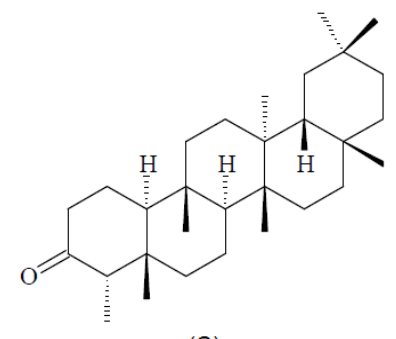

(C)

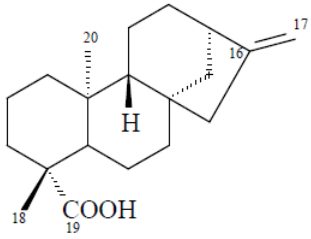

(D)

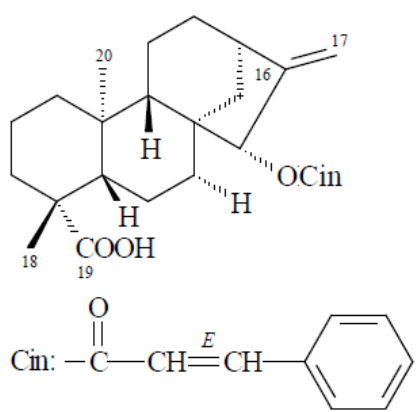

(E)

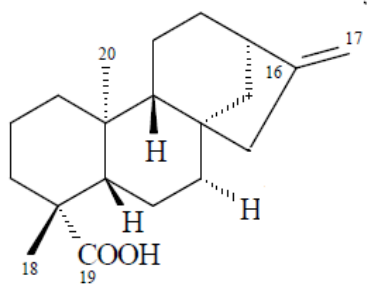

(H)<smiles>CCC(/C=C/[C@H](C)C1CC[C@H]2C3CC=C4CC(O)CCC4(C)C3CCC12C)C(C)C</smiles>

(F)<smiles>C=C1CCC2[C@]3(C)CCC[C@](C)(C(=O)O)C3CC[C@@]2(C)[C@H]1OC(=O)C(C)C</smiles>

(G)

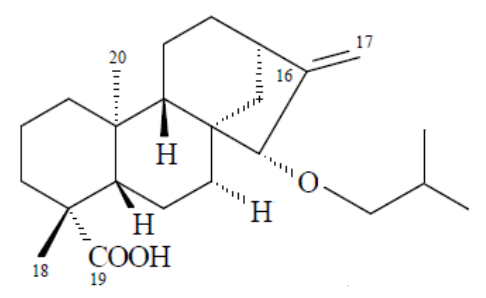

(I)

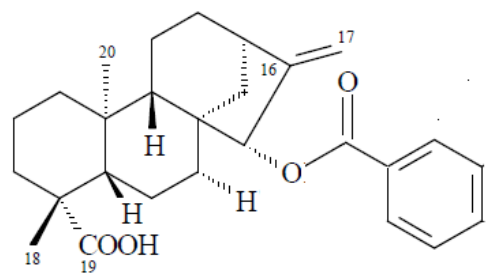

(J)

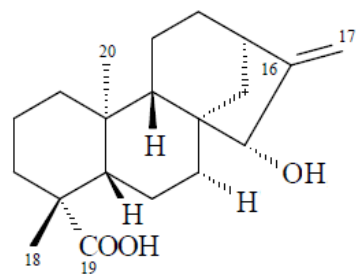

(K)

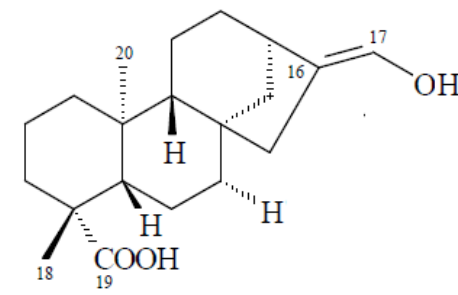

(L)<smiles>O=C(O)C=Cc1ccccc1O</smiles>

(M)

FIGURA 1. Principais constituintes químicos identificados para Mikania glomerata. 
(Taleb-Contini et al., 2006).

Vários estudos científicos comprovam as atividades farmacológicas como bactericida, antiofídica, antialérgica, antifúngica, antiinflamatória, antidiarréica, inibidora da MAO, antimalárica e broncodilatadora para M. glomerata (Fierro et al., 1999; Holetz et al., 2002; Soares et al. (2002); Do Amaral et al., 2003; Falcão et al., 2005; Maiorano et al., 2005; Salgado et al., 2005; Santos et al., 2006; Botsaris, 2007). O objetivo do presente estudo foi determinar propriedades físicoquímicas do pó obtido a partir das folhas de $M$. glomerata, e avaliar a toxicidade em camundongos após tratamento agudo com doses repetidas do extrato etanólico padronizado a $70 \%$ obtido a partir das folhas dessa espécie.

\section{MATERIAL E MÉTODOS}

\section{Preparação da droga utilizada nos tratamentos}

\section{Material Vegetal}

Foi utilizada a parte aérea da espécie M. glomerata Sprengel pertencente à família Asteraceae foi coletada no mês de Maio de 2010 as 08h:00 da manhã no Horto de Plantas Medicinais do Núcleo de Fitoterapia (NUFITO), que faz parte do Núcleo de Assistência Farmacêutica (NUASF) da Secretaria de Saúde do Estado do Ceará (SESA), conforme a exsicata (número 27.041) depositada no Herbário Graziella Barroso da Universidade Federal do Piauí e identificada sua taxonomia pela professora Dra. Roseli Farias Melo de Barros. A retirada de material estranho foi feita manualmente, sendo, então, lavada em água corrente, seguida de água destilada. Após a pesquisa de materiais estranhos, a matéria-prima vegetal foi desidratada à sombra e levada a pó usando moinho de facas.

Preparação do extrato etanólico padronizado a $70 \%$ das folhas de $\mathrm{M}$. glomerata O extrato foi preparado por percolação, com maceração prévia por $24 \mathrm{~h}$ utilizando solução etanólica a 70\%, utilizando-se a proporção de 15 $\mathrm{mL}$ de extrato para cada $1 \mathrm{~g}$ de droga vegetal. A solução extrativa foi então concentrada em estufa com circulação forçada de ar para eliminar o teor alcoólico e aumentar o teor de sólidos, o que correspondeu a uma redução de $75 \%$ do volume inicial. A solução extrativa foi concentrada em rota evaporador, e o resíduo obtido foi dissolvido em solução salina $0,9 \%$ para as dosagens empregadas nos ensaios deste trabalho.

\section{Estudo das propriedades físicoquímicas do pó obtido a partir das folhas de M. glomerata}

\section{Determinação da granulometria}

A determinação da granulometria (tamanho das partículas do pó e distribuição de tamanho) foi realizada seguindo a metodologia prevista na Farmacopéia Brasileira (1988). O procedimento foi desenvolvido mecanicamente, usando um agitador que possui movimentos horizontais e verticais e empregando-se tamises padronizados superpostos, partindo-se de um maior diâmetro ao menor. Uma porção de $30 \mathrm{~g}$ foi colocada no tamis de maior malha e submetida à tamisação durante 30 minutos.

\section{Determinação da densidade bruta e de compactação}

Esses ensaios seguiram as metodologias propostas por Guo e colaboradores (1985) e Cardoso (2002). A amostra foi colocada em provetas previamente pesadas. A densidade de compactação foi determinada com auxílio de volúmetro de compactação. $O$ pó foi submetido a 1250 quedas, segundo a norma DIN 53194. Após essas determinações calculou-se o fator de Hausner determinado através do quociente entre as densidades compactada $(d c)$ e bruta $(d b)$ (Aulton, 2005). O índice de compressibilidade (IC) foi determinado segundo equação $(d c-d b) /$ dc (Wanczinski, 2002).

\section{Determinação do teor de cinzas totais}

A amostra foi reduzida a um pó semifino, pesada e transferida para um cadinho previamente calcinado, resfriado e pesado. Foi levado à ignição a temperatura de $675 \pm 25^{\circ} \mathrm{C}$ (The United States Pharmacopeia, 2007) em forno mufla até que todo material fosse eliminado. A amostra foi resfriada em dessecador e pesado. Foi calculado a porcentagem de cinzas em relação à droga seca à sombra.

\section{Determinação do teor de umidade}

A amostra foi reduzida a um pó fino. Foi pesado exatamente $1 \mathrm{~g}$ da amostra e transferida para pesa-filtro chato previamente dessecado durante 30 minutos nas mesmas condições a serem empregadas na determinação. Foi pesado o pesa-filtro, tampado, contendo a amostra. O pesa-filtro foi agitado brandamente para distribuir a amostra de maneira mais uniforme possível, a uma profundidade ideal de $5 \mathrm{~mm}$. O pesa-filtro foi colocado na estufa, sua tampa foi removida, deixando-a também na estufa. A amostra foi secada a uma temperatura de 105 ${ }^{\circ} \mathrm{C}$ e por um prazo de 2 horas. Em seguida foi resfriada a temperatura ambiente em dessecador,

Rev. Bras. PI. Med., Campinas, v.15, n.4, supl.I, p.742-750, 2013. 
e posteriormente pesada. A operação foi repetida até a obtenção de um peso constante (The United States Pharmacopeia, 2007).

\section{Animais}

Nesse estudo foram utilizados camundongos Swiss (Mus musculus) machos e fêmeas com 2 meses de idade e peso variando entre 25 a 30 g, provenientes do Biotério Central do Centro de Ciências Agrárias da Universidade Federal do Piauí. Os animais receberam água e dieta $\left(\right.$ Labina $\left.^{\circledR}\right)$ ad libitum e foram mantidos sob condições controladas de iluminação (ciclo $12 \mathrm{~h}$ claro/escuro) e temperatura $\left(25 \pm 2^{\circ} \mathrm{C}\right)$. O projeto foi aprovado pelo Comitê de ética em Experimentação com Animais (\#050/2010).

\section{Determinação da dose letal $50 \%\left(D_{50}\right)$ e da toxicidade aguda do extrato etanólico a $70 \%$ das folhas de M. glomerata}

Oitenta camundongos Swiss (Mus musculus) com 2 meses de idade e pesando 25 a $30 \mathrm{~g}$, sendo 40 machos e 40 fêmeas foram divididos em 8 grupos com 10 animais em cada grupo. Os animais foram tratados por via oral durante 30 dias consecutivos com doses de 200, 300, 400, 500, 1000, 2000 e $3000 \mathrm{mg} \mathrm{kg}^{-1}$ do extrato etanólico padronizado a $70 \%$ das folhas de M. glomerata emulsionado em Tween 80 0,05\% dissolvido em solução salina 0,9\% (veículo). E o grupo controle recebeu por via oral durante 30 dias consecutivos $0,25 \mathrm{~mL}$ do veículo (Tween 80 0,05\% dissolvido em solução salina 0,9\%. Durante o período de tratamento foram realizadas observações comportamentais sistemáticas para avaliar o screening hipocrático que fornece uma estimativa geral da toxicidade da substância sobre o estado de consciência e disposição geral, atividade e coordenação do sistema motor, reflexos e atividades sobre os sistemas nervoso central e autônomo (Malone \& Robichaud, 1983). Os parâmetros (atividade geral, frênito vocal, irritabilidade, resposta ao toque, contorção, reflexo de endireitamento, tônus muscular, força para agarrar, ataxia, reflexo auricular, reflexo corneal, tremores, convulsões, calda em straub, hipnose, anestesia, lacrimação, ptose palpebral, micção, defecação, piloereção, hipotermia, respiração, cianose, hiperemia, morte) foram avaliados durante o período de 30 dias consecutivos, a cada dois dias e até o último dia de administração do extrato. Sinais de toxicidade, a época do seu aparecimento, a intensidade, a duração e a progressão dos mesmos foram anotados para posterior análise.

Os animais sobreviventes foram eutanasiados com pentobarbital sódico $40 \mathrm{mg} \mathrm{kg}^{-1}$, conforme protocolo da Cornell University/Cornell Center for Animal Resources and Education, conforme descrito por Flecknell (1996) e Kohn e colaboradores (1997). Foram observados e registrados, diariamente, dados fisiológicos (peso corpóreo, consumo de água, consumo de ração, produção de excretas) e alterações comportamentais anormais durante todo o estudo (Cunha et al., 2009).

O número de mortes de cada grupo foi expresso como o número total de animais que receberam o produto por grupo. A determinação da dose letal $50 \%\left(\mathrm{DL}_{50}\right)$ foi feita através da interpolação semilogarítmica, sendo postos no eixo das ordenadas os valores dos probitos correspondentes ao percentual de mortes e, no eixo das abcissas, as doses administradas de produto.

\section{Análise dos parâmetros bioquímicos e hematológicos}

Quarenta camundongos Swiss (Mus musculus) machos com 2 meses de idade e pesando 25 a $30 \mathrm{~g}$, foram divididos em 4 grupos de 10 animais cada em cada grupo. Os animais foram tratados diariamente por via oral durante 30 dias consecutivos com o veículo (Tween 80 0,05\% dissolvido em solução salina $0,9 \%$; grupo controle) e com as doses de 200, 300 e $400 \mathrm{mg} \mathrm{kg}^{-1}$ do extrato etanólico padronizado $70 \%$ das folhas de $M$. glomerata. Após 30 dias de tratamento os animais foram anestesiados com pentobarbital sódico (40 $\mathrm{mg} \mathrm{kg}{ }^{-1}$, i.p.) e a coleta do sangue foi realizada por punção do plexo venoso orbital, utilizando-se agulhas e seringas e tubos de microhematócrito. $\mathrm{O}$ sangue foi acondicionado em dois tipos de tubo: um com anticoagulante HB (Laborlab ${ }^{\circledR}$ ) para determinação dos parâmetros hematológicos, e o outro, sem anticoagulante, para obtenção do soro para avaliação dos parâmetros bioquímicos.

Os valores para eritrócitos, leucócitos, plaquetas, hemoglobina, hematócrito e os índices hematimétricos volume corpuscular médio (VCM), hemoglobina corpuscular média (HCM) e concentração de hemoglobina corpuscular média (CHCM) foram determinados imediatamente após a coleta por meio de um analisador automático de células hematológicas Advia 120/Hematology Siemens. A contagem diferencial de leucócitos foi realizada em extensões coradas com MayGrünwald-Giemsa. Em cada ensaio, 100 células foram analisadas e contadas.

Para análise bioquímica, o material foi centrifugado a $3500 \mathrm{rpm}$ durante 10 minutos e, em seguida, determinados os parâmetros glicose, uréia, creatinina, aspartato aminotransferase (AST), alanina aminotransferase (AST), colesterol total, triglicerídeos, fosfatase alcalina (ALP), bilirrubinas total e direta, proteínas totais e ácido úrico. Os ensaios foram realizados em aparelho automático Labmax 240 (Labtest) com sistemas comerciais da Labtest $^{\circledR}$. 


\section{Análise morfológica macroscópica dos principais órgãos dos camundongos}

Após a eutanásia dos camundongos, a avaliação macroscópica foi realizada à vista desarmada dos principais órgãos (fígado, pulmão, coração, rim, cérebro e baço). Depois da análise morfológica os órgãos foram pesados para determinar os pesos absolutos (g $100 \mathrm{~g} \mathrm{~g}^{-1}$ ) e verificar se houve ou não alteração morfológica macroscópica nos principais órgãos avaliados.

\section{Análises estatísticas}

Os valores foram expressos como média \pm erro padrão da média (E.P.M.). As diferenças entre os grupos foram determinadas por meio da Análise de Variância (ANOVA), seguida, quando detectada diferença, pelo teste $t$-Student-Newman-Keuls como post hoc teste. O nível de significância para rejeição da hipótese de nulidade foi sempre $\geq$ a $5 \%$.

\section{RESULTADOS E DISCUSSÃO}

TABELA 1. Propriedades físicoquímicas do pó obtido das folhas de M. glomerata

\begin{tabular}{lc}
\hline \multicolumn{1}{c}{ Propriedades Fisicoquimica } & Valores \\
\hline Densidade de compactação $\left(\mathrm{g} \mathrm{mL}^{-1}\right)$ & $0,2757 \pm 0,02$ \\
Densidade bruta $\left(\mathrm{g} \mathrm{mL}^{-1}\right)$ & $0,2105 \pm 0,11$ \\
Teor de umidade $(\%)$ & $12,33 \pm 0,12$ \\
Diâmetro médio $(\mu \mathrm{m})$ & $97,8 \pm 0,07$ \\
Cinzas totais $(\%)$ & $1,174 \pm 0,03$ \\
\hline
\end{tabular}

\section{Propriedades físicoquímicas do pó obtido das folhas de M. glomerata}

Após o estudo em triplicata das propriedades físicoquímicas do pó obtido das folhas de $M$. glomerata foram determinados as seguintes propriedades densidade bruta, densidade de compactação, valor de cinzas totais e diâmetro médio das particular (Tabela 1). Com base na densidade bruta e de compactação foi calculado o Fator de Hausner que correspondeu a 1.30, baseado nos resultados da tabela 1 pode-se sugerir que não haverá problemas durante a sua compressão, uma vez que propriedades de fluidez do pó obtido das folhas do material vegetal estudado apresentaram valores semelhantes aos de outros materiais de fácil compressão (Staniforth 2005; Prescott \& Barnum 2000).

\section{Toxicidade aguda}

O extrato de $M$. glomerata não alterou a massa corpórea dos animais. Também não foram observados sinais clínicos de toxicidade nas doses de $200,300,400$ e $500 \mathrm{mg} \mathrm{kg}^{-1}$ e o registro de morte ocorreu a partir da dose de $1000 \mathrm{mg} \mathrm{kg}^{-1}$ apresentando por via oral a dose letal de $50 \%$ $\left(\mathrm{DL}_{50}\right)$ de $3000 \mathrm{mg} \mathrm{Kg}^{-1}$. Não houve alteração no consumo de água e ração entre os animais acompanhados durante os 30 dias (Tabela 1). É importante considerar que os estudos realizados para determinar a $\mathrm{DL}_{50}$ demonstraram que apenas no grupo de animais fêmeas foram registradas mortes entre esses animais, sugerindo que o ciclo

TABELA 2. Toxicidade aguda após tratamento durante 30 dias com doses repetidas do extrato etanólico padronizado a $70 \%$ de Mikania glomerata em camundongos Swiss.

\begin{tabular}{llllll}
\hline $\begin{array}{l}\text { Dose } \\
\left(\mathbf{m g ~ k g}^{-1}\right)\end{array}$ & $\begin{array}{l}\text { Animais } \\
\text { n/Dose }\end{array}$ & Sexo & D/T & Latência de Morte Sintomas de toxicidade \\
\hline $\mathbf{0}$ & 5 & Fêmeas & $0 / 5$ & - & Nenhum \\
& 5 & Machos & $0 / 5$ & - & Nenhum \\
$\mathbf{2 0 0}$ & 5 & Fêmeas & $0 / 5$ & - & Nenhum \\
& 5 & Machos & $0 / 5$ & - & Nenhum \\
$\mathbf{3 0 0}$ & 5 & Fêmeas & $0 / 5$ & - & Nenhum \\
& 5 & Machos & $0 / 5$ & - & Nenhum \\
$\mathbf{4 0 0}$ & 5 & Fêmeas & $0 / 5$ & - & Nenhum \\
& 5 & Machos & $0 / 5$ & - & Nenhum \\
$\mathbf{5 0 0}$ & 5 & Fêmeas & $0 / 5$ & - & Nenhum \\
& 5 & Machos & $0 / 5$ & - & Conhum \\
$\mathbf{1 0 0 0}$ & 5 & Fêmeas & $1 / 5$ & $<12 \mathrm{~h}$ & Contorções e taquicardia \\
& 5 & Machos & $0 / 5$ & $<12 \mathrm{~h}$ & Contorções, taquicardia \\
$\mathbf{2 0 0 0}$ & 5 & Fêmeas & $2 / 5$ & $<12 \mathrm{~h}$ & Contorções, taquicardia e piloereção \\
& 5 & Machos & $0 / 5$ & $<12 \mathrm{~h}$ & $<12 \mathrm{~h}$ \\
$\mathbf{3 0 0 0}$ & 5 & Fêmeas & $5 / 5$ & $<12 \mathrm{~h}$ & \\
& 5 & Machos & $0 / 5$ & $<$.
\end{tabular}

Legenda: $\mathbf{n} /$ dose $=$ número de animais por dose; $\mathbf{D}=$ número de mortes; $\mathbf{T}=$ número de animais tratados;

Rev. Bras. PI. Med., Campinas, v.15, n.4, supl.I, p.742-750, 2013. 
estral pode influenciar a toxicidade desse extrato. Entretanto, essa toxicidade embora não tenha significado clínico ainda necessita de mais estudos para verificar os efeitos desse extrato sobre a toxicidade reprodutiva.

Segundo latsyno (1978) o acompanhamento da massa corpórea do animal é um importante indicador para a avaliação da toxicidade de uma substância. Dessa forma, pode-se sugerir que o extrato etanólico pradrozinado a $70 \%$ das folhas de M. glomerata é seguro uma vez que não produziu nenhuma mudança nesse parâmetro durante 0 screening Hipocrático.

\section{Parâmetros bioquímicos}

Em nossos estudos para avaliar a toxicidade aguda na análise dos parâmetros bioquímicos, não foi verificado alteração na concentração sanguínea da maioria dos parâmetros bioquímicos avaliados dos camundongos tratados com o extrato etanólico durante 30 dias consecutivos (Tabela 3). Por sua vez, os níveis de creatinina entre os animais dos grupos tratados com extrato de $M$. glomerata nas doses de 200 e $300 \mathrm{mg} \mathrm{kg}^{-1}$ em relação ao grupo controle. Por outro lado, quando comparamos a dose de $400 \mathrm{mg} \mathrm{kg}^{-1}$ do extrato, verificamos um aumento de $60 \%$ nos níveis de creatinina em relação ao grupo controle e os níveis de uréia dos grupos tratados com as mesmas doses (200, 300 e $\left.400 \mathrm{mg} \mathrm{kg}^{-1}\right)$ verificou-se uma redução de $29,3,20,3$ e $62,7 \%$, respectivamente, em relação ao grupo controle.

Dessa forma, por meio de um aumento apenas na dose de $400 \mathrm{mg} \mathrm{Kg}^{-1}$ podem sugerir pequenas modificações na concentração da creatinina, bem como pela ausência de alterações observadas nos níveis da uréia pode-se sugerir que o extrato de M. glomerata produz apenas alterações primárias das condições renais sem significado clínico.

Pode-se verificar também alteração nos níveis de triglicerídeos e de colesterol total nos grupos tratados com o extrato de M. glomerata nas doses de 200, 300 e $400 \mathrm{mg} \mathrm{kg}^{-1}$ em relação ao grupo controle, havendo uma redução em ambos os níveis. Por sua vez nos níveis de triglicerídeos a redução foi de 34,2, 18,8 e 34,8\%, respectivamente. Nos níveis de colesterol total a redução foi de 19,3, 20,2 e $17,7 \%$, respectivamente para as doses avaliadas do extrato (Tabela 3 ).

Durante a avaliação da toxicidade aguda, também foram determinados os níveis sanguíneos de ácido úrico em camundongos tratados com o extrato de M. glomerata nas doses de 200, 300 e $400 \mathrm{mg} \mathrm{kg}^{-1}$ por via oral. Foi verificada alteração na concentração sanguínea de ácido úrico, caracterizada por uma redução de 66,6, 96,2 e $65,9 \%$, respectivamente, em comparação ao grupo controle, sugerindo que o extrato de M. glomerata pode não induzir o desenvolvimento de cálculo renal, uma vez que não alterou o metabolismo do ácido úrico nos rins.

\section{Parâmetros hematológicos}

O hemograma é um exame laboratorial que permite avaliar de forma quantitativa e qualitativa os elementos figurados do sangue. É composto pelo eritrograma, leucograma e palquetograma. No eritrograma é executado a contagem de eritrócitos, a dosagem de hemoglobina, a determinação do hematócrito, o volume corpuscular médio (VCM), o hemoglobina corpuscular média (HCM), a concentração de hemoglobina corpuscular média (CHCM) e a amplitude de distribuição dos eritrócitos. Sendo observado no presente trabalho

TABELA 3. Parâmetros bioquímicos obtidos do soro de camundongos Swiss, tratados com o extrato etanólico padronizado a $70 \%$ obtido das folhas de Mikania glomerata administrado por via oral durante 30 dias consecutivos.

\begin{tabular}{|c|c|c|c|c|}
\hline Parâmetros & $\begin{array}{c}\text { Controle } \\
(n=10)\end{array}$ & $\begin{array}{c}\text { MG } 200 \\
(n=10)\end{array}$ & $\begin{array}{c}\text { MG } 300 \\
(n=10)\end{array}$ & $\begin{array}{c}\text { MG } 400 \\
(n=10)\end{array}$ \\
\hline Glicose $\left(\mathrm{mg} \mathrm{dL}^{-1}\right)$ & $93,14 \pm 1,47$ & $95,50 \pm 1,32$ & $92,09 \pm 2,07$ & $96,70 \pm 1,93$ \\
\hline Uréia $\left(\mathrm{mg} \mathrm{dL}^{-1}\right)$ & $54,67 \pm 0,30$ & $38,70 \pm 3,80^{a}$ & $43,60 \pm 4,44^{a}$ & $20,40 \pm 1,54^{a}$ \\
\hline Creatinina $\left(\mathrm{mg} \mathrm{dL}^{-1}\right)$ & $0,43 \pm 0,43$ & $0,47 \pm 0,31$ & $0,47 \pm 0,58$ & $0,69 \pm 0,94^{a}$ \\
\hline Ácido úrico $\left(\mathrm{mg} \mathrm{dL}^{-1}\right)$ & $2,61 \pm 0,04$ & $0,87 \pm 0,12^{a}$ & $0,90 \pm 0,09^{a}$ & $0,89 \pm 0,09^{a}$ \\
\hline Triglicerídeos $\left(\mathrm{mg} \mathrm{dL}^{-1}\right)$ & $106,7 \pm 0,05$ & $70,20 \pm 6,07^{a}$ & $86,60 \pm 7,83^{a}$ & $69,50 \pm 7,24^{a}$ \\
\hline $\mathrm{CT}\left(\mathrm{mg} \mathrm{dL}^{-1}\right)$ & $82,35 \pm 2,47$ & $66,50 \pm 4,49^{a}$ & $65,80 \pm 4,79^{a}$ & $67,80 \pm 4,85^{a}$ \\
\hline Proteínas totais $\left(\mathrm{mg} \mathrm{dL}^{-1}\right)$ & $6,10 \pm 0,25$ & $5,97 \pm 0,13$ & $6,15 \pm 0,12$ & $6,32 \pm 0,23$ \\
\hline AST $\left(\mathrm{U} \mathrm{mL}^{-1}\right)$ & $90,33 \pm 2,09$ & $91,40 \pm 3,01$ & $92,60 \pm 2,93$ & $91,10 \pm 3,32$ \\
\hline $\operatorname{ALT}\left(U \mathrm{~mL}^{-1}\right)$ & $61,34 \pm 1,43$ & $60,90 \pm 1,86$ & $61,60 \pm 2,18$ & $61,00 \pm 1,21$ \\
\hline Fosfatase alcalina $\left(\mathrm{U} \mathrm{I}^{-1}\right)$ & $157,60 \pm 0,97$ & $156,10 \pm 1,30$ & $163,40 \pm 4,71$ & $166,50 \pm 4,54$ \\
\hline Bilirrubina total $\left(\mathrm{mg} \mathrm{dL}^{-1}\right)$ & $0,26 \pm 0,02$ & $0,25 \pm 0,06$ & $0,25 \pm 0,02$ & $0,27 \pm 0,03$ \\
\hline Bilirrubina direta $\left(\mathrm{mg} \mathrm{dL}^{-1}\right)$ & $0,15 \pm 0,01$ & $0,12 \pm 0,00$ & $0,13 \pm 0,00$ & $0,17 \pm 0,03$ \\
\hline
\end{tabular}

Legenda: Os valores representam a média \pm E.P.M. do número de animais usados nos experimentos. $n-$ representa o número de animais em cada grupo. ${ }^{a} \mathrm{p}<0,05$, quando comparados ao grupo controle (ANOVA e teste $t$-Student-Newman-Keuls como post hoc teste);

Rev. Bras. PI. Med., Campinas, v.15, n.4, supl.I, p.742-750, 2013. 
se há presença ou ausência de significância entre seus valores. Nesse estudo pode-se observar uma alteração significativa entre esses valores, uma vez que para o valor do VCM, houve um aumento de 18,5, 21,7 e 13\% em relação ao grupo controle, com os grupos tratados com o extrato de $M$. glomerata nas doses de 200, 300 e $400 \mathrm{mg} \mathrm{kg}^{-1}$, respectivamente (Tabela 4).

No eritrograma pode-se avaliar o eritrônio, cuja função é o transporte de oxigênio do pulmão aos tecidos, podendo ser exercido pelo conteúdo hemoglobínico, sendo sua fisiopatologia essencialmente quantitativa. Assim, a insuficiência funcional do eritrônio, anemia, é definida como diminuição da hemoglobina sanguínea; esta costuma acompanhar-se, mas não necessariamente de modo paralelo, de diminuição do número de eritrócitos Failace (2009). Já a HCM, apresentou um aumento, sendo este de $46,4 \%$ com os grupos tratados nas doses de 200 e $300 \mathrm{mg} \mathrm{kg}^{-1}$ em relação ao grupo controle, e de $36,7 \%$ na dose de $400 \mathrm{mg}$ $\mathrm{kg}^{-1}$ (Tabela 4).

Por fim, após o tratamento durante 30 dias administrado por via oral com o extrato etanólico padronizado a $70 \%$ das folhas de $M$. glomerata nas doses de 200, 300 e $400 \mathrm{mg} \mathrm{kg}^{-1}$ não foram verificadas mudanças no perfil hematológico entre os camundongos (Tabela 4).

$\mathrm{Na}$ avaliação da análise morfológica macroscópica dos principais órgãos não verificouse nenhuma alteração nos órgãos avaliados (Tabela 5). De acordo com a literatura o extrato hidro-alcoólico de partes aéreas da mesma espécie não demonstrou efeitos tóxicos, uma vez que não observamos alteração do peso corpóreo e dos principais órgãos de ratos Wistar (Sá et al. 2003). Por outro lado, em um estudo realizado por Graça (2004) foi verificado que o extrato etanólico da espécie Mikania laevigata Schultz Bip. Ex Baker também pertencente à mesma família da espécie estudada produziu alterações morfológicas macroscópicas do tipo fibrose pulmonar e dilatação pielocalicial renal em animais tratados com uma única dose da solução ou do xarope de partes aéreas de $M$. leviagata. Nesse mesmo estudo também foram observados alterações na massa relativa dos rins e do fígado.

Dessa forma, nosso estudo por meio dos resultados obtidos na avaliação da toxicidade aguda demonstra que o extrato etanólico padronizado a $70 \%$ das folhas de $M$. glomerata pode ser usado de forma segura, uma vez que não induziu mudanças com significado clínico no perfil hematológico e bioquímico, bem como apresentou um valor para dose letal $50 \%\left(\mathrm{DL}_{50}\right)$ que é considerada nociva segundo Crowl (1995).

Os ensaios pré-clínicos realizados são importantes para garantir a segurança e eficácia do extrato nas doses testadas (200, 300 e $400 \mathrm{mg}$ $\mathrm{kg}^{-1}$ ), visto que os animais não apresentaram sinais clínicos de toxicidade durante o tratamento com esse extrato.

Na literatura de bases de dados de patente, verificou-se que extratos preparados a partir da M. glomerata são geralmente empregados no tratamento de doenças respiratórias em humanos. Podem ser citados como exemplo o pedido de registro de patente PI 9903296-1, que descreve um processo para obtenção de frações a partir do extrato etanólico das folhas de Mikania glomerata, com atividade dilatadora da musculatura lisa respiratória, antiedema e antialérgica. E a solicitação de um pedido registro de depósito de patente para a formulação, que consiste de um xarope feito à base de guaco em associação com outras plantas,

TABELA 4. Parâmetros hematológicos de camundongos Swiss, tratados com o extrato etanólico padronizado a $70 \%$ de Mikania glomerata administrado por via oral durante 30 dias consecutivos.

\begin{tabular}{|c|c|c|c|c|}
\hline Parâmetros & $\begin{array}{c}\text { Controle } \\
(n=10)\end{array}$ & $\begin{array}{c}\text { MG } 200 \\
(n=10)\end{array}$ & $\begin{array}{c}\text { MG } 300 \\
(n=10)\end{array}$ & $\begin{array}{c}\text { MG } 400 \\
(n=10)\end{array}$ \\
\hline Hemácias $\left(\mathrm{mm}^{3}\right)$ & $8,22 \pm 0,24$ & $8,18 \pm 0,32$ & $8,11 \pm 0,28$ & $8,54 \pm 0,25$ \\
\hline Hemoglobina $\left(\mathrm{g} \mathrm{dL}^{-1}\right)$ & $13,36 \pm 0,05$ & $12,12 \pm 0,54$ & $12,44 \pm 0,54$ & $14,09 \pm 0,51$ \\
\hline Hematócrito (\%) & $41,24 \pm 1,32$ & $40,46 \pm 1,75$ & $41,44 \pm 1,72$ & $39,81 \pm 1,62$ \\
\hline VCM (fL) & $49,67 \pm 0,04$ & $58,90 \pm 2,56^{a}$ & $60,50 \pm 3,02^{a}$ & $56,20 \pm 1,08^{a}$ \\
\hline HCM (pg) & $16,64 \pm 0,03$ & $24,28 \pm 1,20^{a}$ & $24,27 \pm 0,82^{a}$ & $22,69 \pm 1,37^{a}$ \\
\hline CHCM (\%) & $35,93 \pm 0,38$ & $36,01 \pm 1,04$ & $36,16 \pm 1,11$ & $35,84 \pm 0,50$ \\
\hline Plaquetas $\left(\mathrm{mm}^{3}\right)$ & $442,40 \pm 27,07$ & $442,90 \pm 20,31$ & $441,40 \pm 17,76$ & $442,40 \pm 16,17$ \\
\hline Leucócitos totais $\left(\mathrm{mm}^{3}\right)$ & $4,92 \pm 0,33$ & $4,73 \pm 0,54$ & $4,78 \pm 0,50$ & $4,14 \pm 0,28$ \\
\hline Neutrófilos (\%) & $16,60 \pm 0,88$ & $17,38 \pm 1,33$ & $17,28 \pm 1,14$ & $17,11 \pm 1,16$ \\
\hline Eosinófilos (\%) & $0,35 \pm 0,01$ & $0,33 \pm 0,03$ & $0,35 \pm 0,04$ & $0,34 \pm 0,07$ \\
\hline Linfócitos (\%) & $73,99 \pm 2,60$ & $71,00 \pm 3,48$ & $70,10 \pm 2,84$ & $77,10 \pm 2,54$ \\
\hline
\end{tabular}

Legenda: Os valores representam a média \pm E.P.M. do número de animais usados nos experimentos. $\mathrm{n}-$ representa o número de animais em cada grupo. ${ }^{a} p<0,05$, quando comparados ao grupo controle (ANOVA e teste $t$-Student-Newman-Keuls como post hoc teste);

Rev. Bras. PI. Med., Campinas, v.15, n.4, supl.I, p.742-750, 2013. 
TABELA 5: Análise morfológica macroscópica de camundongos Swiss, tratados com extrato etanólico padronizado a $70 \%$ das folhas de Mikania glomerata administrado via oral durante 30 dias consecutivos.

\begin{tabular}{lcccc}
\hline \multicolumn{1}{c}{ Órgãos } & $\begin{array}{c}\text { Controle } \\
(\mathbf{n = 1 0})\end{array}$ & $\begin{array}{c}\text { MG 200 } \\
(\mathbf{n}=\mathbf{1 0})\end{array}$ & $\begin{array}{c}\text { MG 300 } \\
(\mathbf{n = 1 0})\end{array}$ & $\begin{array}{c}\text { MG 400 } \\
(\mathbf{n}=\mathbf{1 0})\end{array}$ \\
\hline Coração & $0,13 \pm 0,03$ & $0,10 \pm 0,02$ & $0,12 \pm 0,04$ & $0,11 \pm 0,03$ \\
Fígado & $0,82 \pm 0,01$ & $0,79 \pm 0,01$ & $0,81 \pm 0,01$ & $0,82 \pm 0,01$ \\
Baço & $0,07 \pm 0,03$ & $0,08 \pm 0,02$ & $0,07 \pm 0,03$ & $0,08 \pm 0,03$ \\
Rim & $0,11 \pm 0,02$ & $0,10 \pm 0,03$ & $0,11 \pm 0,03$ & $0,10 \pm 0,01$ \\
Cérebro & $0,15 \pm 0,04$ & $0,15 \pm 0,01$ & $0,16 \pm 0,01$ & $0,16 \pm 0,02$ \\
Pulmão & $0,15 \pm 0,01$ & $0,15 \pm 0,02$ & $0,15 \pm 0,02$ & $0,15 \pm 0,04$ \\
\hline
\end{tabular}

Legenda: Os valores representam a média \pm E.P.M. dos valores expressos em termos de massa absoluta $\left(\mathrm{g} 100 \mathrm{~g}^{-1}\right)$ do número de animais usados nos experimentos. $\mathrm{n}$ - representa o número de animais em cada grupo.

é indicada para auxiliar no tratamento de bronquite, tosse e como expectorante, especialmente para fumantes.

Com base em nossos estudos durante a avaliação das propriedades físicoquímicas do pó obtido a partir das folhas de M. glomerata sugere-se que o pó pode ser usado na formulação de uma forma farmacêutica sólida, bem como o extrato etanólico pode ser usado de forma segura em ensaios pré-clínicos, uma vez que apresentou um valor para a $\mathrm{DL}_{50}$ que pode ser classificado na categoria nociva, bem como não produziu nenhuma alteração morfológica nos principais órgãos e em parâmetros bioquímicos e hematológicos de camundongos.

Os dados do presente estudo, bem como por meio de outros resultados do nosso grupo de pesquisa foi solicitado um pedido de registro de depósito de patente para o extrato estudado sob o número PI 1107225-3 intitulado: "Formulações farmacêuticas a partir do extrato etanólico das folhas de Mikania glomerata Sprengel".

\section{REFERÊNCIA}

AULTON, M.E. Delineamento de formas farmacêuticas. Porto Alegre: Artmed, 2005.

BREMER, K. Asteraceae. Cladistics and Classification. Portland, Oregon: Timber Press,1994.752p.

BOTSARIS, A.S. Plants used traditionally to treat malaria in Brazil: the archives of Flora Medicinal. Journal Ethnobiology Ethnomedicine, v.1, p.13-18, 2007.

CARDOSO, M.LC. Desenvolvimento de metodologias analíticas e tecnológica na obtenção de extratos secos nebulizados de Heteropteris afrodisíaca 0. Madi. O - Malpighiaceae. 2002. 128p. Tese (Doutorado em Ciências Farmacêuticas) - Faculdade de Ciências Farmacêuticas, Universidade Estadual Paulista, Araraquara.

CELEGHINI, M.S. et al. Extraction and quantative HPLC analysis of coumarin in hydroalcoholic extracts of Mikania glomerata Sprengel "guaco" leaves. Journal of the Brazilian Chemical Society, v.12, p.706-09, 2001. CUNHA, C.L. et al. Avaliação da toxicidade aguda e subaguda, em ratos, do extrato etanólicodas folhas e do látex de Synadenium umbellatum Pax. Revista Brasileira de Farmacognosia, v.19, n.2A, p.403-11, 2009.

CROWL, D.A. Introduction Toxic and Highly toxic Chemicals. In: Stanley S.G. and Daniel A.C. Handbook of highly toxic materials handling and management, $1^{\text {a }}$ ed., Chapter 1, Marcel Dekker Inc. New York, USA, 1995.

DO AMARAL, R.R. et al. Avaliação da atividade iMAO e anti-bacteriana de extratos de Mikania glomerata Sprengel. Revista Brasileira de Farmacognosia, v.13, p.24-27, 2003.

FAILACE, R. Hemograma; Manual de Interpretação. $5^{a}$ ed., Porto Alegre: Artes Médicas, 2009. 424p.

FALCÃO, H.S. et al. Review of the plants with anti-infl ammatory activity studied in Brazil. Revista Brasileira de Farmacognosia, v.15, p.381-91, 2005.

FARMACOPEIA BRASILEIRA. 4 ${ }^{a}$ Ed. São Paulo: Atheneu, 1988.

FIERRO, I.M. et al. Studies on the anti-allergic activity of Mikania glomerata. Journal of Ethnopharmacology, v.66, p.19-24, 1999.

GRAÇA, C. Determinação da toxicidade pré-clínica do xarope de guaco (Mikania laevigata Schultz Bip. Ex Baker) em roedores. 2004. 116p. Dissertação (Mestrado em Ciências Farmacêuticas) Ciências da Saúde, Universidade Federal do Paraná, Curitiba.

FLECKNELL, P. Laboratory Animal Anesthesia. $2^{\mathrm{a}}$ ed. New York: Academic Press, 1996. 274p.

GUO, A. et al. A simple relationship between particle shape effects and density, flow rate and hausner ratio. Powder Technology, v.43, p.279-284, 1985.

HEBERLÉ,G. et al. Caracterização do produto seco por aspersão de Cecropia glazioui Sneth. (Cecropiaceae). Acta Farmaceutica Bonaerense v.19, n.3, p. 203-210 2000.

HOLETZ, F.B. et al. Screening of some plants used in the brazilian folk medicine for the treatment of infectious diseases. Memórias do Instituto Oswaldo Cruz, v.97,p.1027-31, 2002.

IATSYNO, A.I. et al. Pharmacology of Calenduloside B - A new terpene glycoside obtained from the roots of Calendula officinalis. Farmakologiia i toksikologiia, v.41, p.550-60, 1978.

$\mathrm{KOHN}$, D.F. et al. Anesthesia and Analgesia in Laboratory Animals. ACLAM, Academic Press, New York. 1997. 426p. 
LEITE, M.G.R. et al. Estudo Farmacológico comparatiivo de Mikania glomerata Spreng. (guaco), Justicia pectoralis Jacq (anador) e Torresea cearensis (cumaru). Revista Brasileira de Farmácia, v.74, n.1, p.12-15, 1993.

LUCAS, V. Estudo farmacognóstico do guaco Mikania glomerata Sprengel. Revista da Flora Medicinal, v. 9, p.101-32, 1942.

MAIORANO, A.V. et al. Antiophidian properties of the aqueous extract of Mikania glomerata. Journal of Ethnopharmacology, v.102, p.364-70, 2005.

MALONE, M.H., ROBICHAUD, R.C. A Hippocratic screen for pure or crude drug materials. Lloydia, v. 25, p. 32032, 1962.

OLIVEIRA, F. et al. Parâmetros físicos e químicos e efeito antiedema dos extratos fluidos de guaco (Mikania glomerata Spreng.) e de guaco de mato (Mikania laevigata Schutz Bip.ex Baker). Anais de Farmácia e Química, v. 25, n. 1/2, p. 50-54, 1985.

OLIVEIRA, F. Contribuição para o estudo botânico de Mikania hirsutissima DC. var hirsutissima. II Morfologia externa e anatomia da folha, flor, fruto e semente. Revista de Farmácia e Bioquímica, v. 10, p.15-36, 1972.

OLIVEIRA, F. et al. Isolamento e identificação de componentes químicos de Mikania glomerata Sprengel e de Mikania laevigata Schultz Bip, ex Baker. Revista de Farmácia e Bioquímica, v. 20, n. 2, p.169-83, 1984.

PANIZZA, S. Plantas que Curam: cheiro de mato. $25^{\circ}$ ed. São Paulo: IBRASA, 1997. 280p.

PIO CORRÊA, M. Dicionário das plantas úteis do Brasil e das exóticas cultivadas. $2^{\circ}$ ed., Rio de Janeiro, 1984. $707 p$.

PRESCOTT, J.K. \& BARNUM, R.A. Sobre a fluidez de pós. Pharmaceutical Technology, v. 4, n. 6, p.16-30, 2000.

RITTER, M.R. \& MIOTTO, S.T.S. Taxonomia de Mikania Willd. (Asteraceae) no Rio Grande do Sul, Brasil.
Hoehnea, v.32, p. 309-59, 2005.

SÁ, R.C.S. Evaluation of long-term exposure to Mikania glomerata (Sprengel) extract on male Wistar rats' reproductive organs, sperm production and testosterone level. Contraception, v.67, p. 327-31, 2003.

SALGADO, H.R.N. et al. Antidiarrhoeal effects of Mikania glomerata Spreng. (Asteraceae) leaf extract in mice. Revista Brasileira de Farmacognosia, v.15, p. 20508, 2005.

SANTOS, S.C. et al. LC characterisation of guaco medicinal extracts, Mikania laevigata and M. glomerata, and their effects on allergic pneumonitis. Planta Medica, v.72, n.8, p.679-84, 2006.

SOARES, M.R. et al. Bronchodilator activity of Mikania glomerata Sprengel on human bronchi and guinea-pig trachea. Journal of Pharmacy and Pharmacology, v.54, p.249-56, 2002.

STANIFORTH, J.N. Fluxo de pós. In: AULTON, M. E., (Ed.). Delineamento de formas farmacêuticas. $2^{\mathrm{a}} \mathrm{ed}$. Porto Alegre: Artmed, 2005. 208-221p.

TALEB-CONTINI, S.H. et al. Differences in secondary metabolites from leaf extracts of Mikania glomerata Sprengel obtained by micropropagation and cuttings. Revista Brasileira Farmacognosia, v.16, p.596-98, 2006.

TESKE, M. \& TRENTINI, A.M.M. Herbarium Compêndio de Fitoterapia. $3^{a}$ ed. Herbarium, Curitiba, PR. p.160, 1997. 317p.

The United States Pharmacopeia. 30th ed. Rockville: United States Pharmacopoeial Convention, 2007.

VENEZIANI, R.C.S. \& OLIVEIRA, D.C.R. Constituents of Mikania glomerata. Biochemical Systematics and Ecology, v.27, n.1, p.99-102, 1999.

WANCZINSKI, B.J. et al. Desenvolvimento de comprimidos de AAS 500 mg: influência do Amido $1500^{\circledR}$ na compressão direta. Acta Scientiarum. v.24, n.3, p.649655, 2002.

Rev. Bras. PI. Med., Campinas, v.15, n.4, supl.I, p.742-750, 2013. 